\title{
Analysis of risk factors associated with caesarean section surgical site infections: a case control study
}

\author{
Riya Rano*, Purvi K. Patel
}

Department of Obstetrics and Gynecology, Government Medical College, Baroda, Gujarat, India

Received: 07 October 2020

Revised: 11 November 2020

Accepted: 12 November 2020

\section{*Correspondence:}

Dr. Riya Rano,

E-mail: riyarano5@gmail.com

Copyright: (c) the author(s), publisher and licensee Medip Academy. This is an open-access article distributed under the terms of the Creative Commons Attribution Non-Commercial License, which permits unrestricted non-commercial use, distribution, and reproduction in any medium, provided the original work is properly cited.

\begin{abstract}
Background: Surgical site infection (SSI) is defined as infection occurring within 30 days after a surgical procedure and affecting either the incision or deep tissues at the operation site. SSIs are the most common nosocomial infections, accounting for $38 \%$ of hospital-acquired infections. Despite the advances in SSI control practices, SSIs remain common causes of morbidity and mortality among hospitalized patients. This study was undertaken with an objective to determine and analyze the risk factors associated with cesarean section SSIs.

Methods: The study was carried out at Medical College and SSG Hospital, Baroda. After obtaining informed consent to be a part of the study, 140 subjects having cesarean section SSI as per the definition, were included as cases in the study. The controls (140) were also selected from the hospital subjects. The primary post-operative care was similar for the cases as well as controls. For patients who had SSI, samples of discharge from the cesarean section wound were collected and transported for culture. Antibiotics were given accordingly. Details about patient characteristics and outcomes were collected in the proforma for cases and controls and data analyzed.

Results: The cesarean section SSI rate was $4.78 \%$. Of the parameters studied, maternal age, parity, gestational age, HIV status, meconium stained amniotic fluid, amount of blood loss, previous surgery, duration of surgery were not associated with cesarean section SSI.

Conclusions: Number of antenatal care (ANC) visits, haemoglobin, total white blood cells (WBC) count, pre eclampsia, premature rupture of membranes (PROM), non-progression in 2nd stage and subcutaneous tissue thickness were the independent significant risk factors associated with post-cesarean SSI.
\end{abstract}

Keywords: SSI, Cesarean section, Risk factors

\section{INTRODUCTION}

A surgical site infection is defined as an infection which occurs at the incision/operative site (including drains) within 30 days after surgical procedure if no implant is left in place/within one year if an implant is left in place. The infection must appear related to the surgical procedure. ${ }^{1}$

Surgical site infection (SSI) is classified as superficial, deep and organ/space infection, which occurs within 30 days after the operation.

\section{Superficial SSI}

It is infection which involves only skin and subcutaneous tissue of the incision and presence of any one of the mentioned conditions like, purulent drainage with or without laboratory confirmation, organism isolated from superficial incision, presence of sign and symptoms of infection at the site and diagnosis of SSI by surgeon where stitch abscess and infection of an episiotomy are not included. 


\section{Deep incisional SSI}

It is infection involving deep soft tissues (e.g. fascial and muscle layers) of the incision and at least one of these, purulent drainage from the deep incision, deep incision spontaneously dehisces or is deliberately opened by a surgeon when the patient has at least one of the following signs or symptoms: fever $\left(>38{ }^{\circ} \mathrm{C}\right)$, localized pain, or tenderness, unless site is culture-negative, an abscess or other evidence of infection involving the deep incision. Diagnosis of a deep incisional SSI by attending surgeon.

Infection that involves both superficial and deep incision sites will be reported as deep incisional SSI and an organ/space SSI that drains through the incision as a deep incisional SSI.

\section{Organ/space SSI}

It is infection, which involves any part of the anatomy (e.g. organs or spaces), other than the incision, which was opened or manipulated during an operation and at least one of the following, purulent drainage from a drain that is placed through a stab wound into the organ/space, organisms isolated from an aseptically obtained culture of fluid or tissue in the organ/space, an abscess or other evidence of infection involving the organ/space that is found on direct examination, during re-operation, or by histopathologic or radiologic examination and diagnosis of an organ/space SSI by attending surgeon.

According to centers for disease control and prevention's (CDC) national nosocomial infection surveillance system $38 \%$ of all nosocomial infections in surgical patients are SSI. Cesarean section, one of the most common surgical procedures in obstetrics, falls in clean-contaminated wounds category. SSI is the second most common infectious complication following cesarean section after urinary tract infection (UTI). Its incidence ranges from 3$15 \%$. Cesarean section SSI delays the recovery, prolongs hospitalization, necessitates readmission, and adds to hospital bills and other morbidities as well as mortalities. ${ }^{1}$ This study was undertaken to analyze the risk factors causing cesarean section SSI as it would help in incorporating measures to decrease the rate of the same.

\section{METHODS}

This study was conducted in obstetrics ward of SSG Hospital over the duration of 1 year, from 1st November 2018 to 31st October 2019. The subjects undergoing cesarean section at the department and having SSI as defined above were enrolled as cases. The control group consisted of patients who were determined after the inclusion of case patients and fulfilled to the following inclusion criteria: similar age ( \pm 2 years), cesarean section performed on the same day as the case patient and no history of post-cesarean infectious complication up to the 30th day, taking into account the CDC/NHSN criteria. Exclusion criterias were, subjects not giving consent to participate in the study, clinical case records not available, subjects having a vaginal or perineal surgery in addition to cesarean section, subjects requiring obstetric hysterectomy/any other surgical complication, subjects operated outside SSG Hospital and referred here for further management and subjects who died before the third post-operative day. During the study period, 140 cases and 140 controls were enrolled. All cases undergoing cesarean section were routinely given antibiotics half an hour prior to surgery and then for at least 7 days. The patients were routinely monitored daily for any signs of SSIs as per the CDC definition. For patients who had SSI, samples of discharge from the cesarean section wound were collected and immediately transported to the microbiology laboratory for culture.

Risk factors were divided into three categories: hostrelated factors, pregnancy and intrapartum-related factors and procedure-related factors.

\section{Host-related factors}

These included maternal age, obesity, parity, anemia, perioperative blood transfusion, co-existent infection at remote site, hepatitis B status, human-immunodeficiency virus (HIV) status, antenatal care, previous cesarean delivery, maternal pre-operative condition (American society of anesthesiologists score).

\section{Pregnancy and intrapartum-related factors}

These included gestational age, hypertensive disorder, gestational diabetes mellitus, twin pregnancy, premature rupture of membranes, greater number of vaginal examinations, prolonged trial of labor prior to surgery, chorioamnionitis, and meconium staining of amniotic fluid.

\section{Procedure-related factors}

These included type of surgery (elective/emergency), indication, type of anesthesia, type of incision, duration of surgery, amount of blood loss, cadre of operating surgeon, subcutaneous tissue thickness, subcutaneous tissue sutured or not, skin closure (subcuticular/mattress).

The data was collected in the proforma both from the records and from the study participants (if required) and then entered in an excel sheet. Categorical variables were presented in number and percentage (\%) and continuous variables were presented as mean \pm standard deviation (SD) and median. Normality of data was tested by KolmogorovSmirnov test. If the normality was rejected then nonparametric test was used.

\section{Statistical tests}

Quantitative variables were compared using MannWhitney test (as the data sets were not normally distributed) between the two groups. 
Qualitative variables were correlated using Chi-square test/Fisher's exact test.

Multivariate forward conditional logistic regression was used to find out significant risk factors of surgical site infection.

A p value of $<0.05$ was considered statistically significant.

The data was entered in Microsoft excel spreadsheet and analysis was done using statistical package for social sciences (SPSS) version 21.0.

\section{RESULTS}

There were total 2925 caesarean sections and 140 SSI that makes the caesarean section wound infection rate of $4.78 \%$. After applying inclusion/exclusion criteria, 280 women were included in the study: Cases and control groups included 140 women each. Data related to hostrelated factors, pregnancy and intrapartum-related factors, and procedure-related factors was recorded. Following were the results related to the study.

Table 1: Distribution of SSI category of cases.

\begin{tabular}{|lll|}
\hline SSI category & Frequency & Percentage \\
\hline Discharge & 2 & 1.43 \\
\hline Full length wound gap & 118 & 84.29 \\
\hline $\begin{array}{l}\text { Partial length wound } \\
\text { gap }\end{array}$ & 7 & 5.00 \\
\hline Superficial discharge & 1 & 0.71 \\
\hline Wound discharge & 12 & 8.57 \\
\hline Total & 140 & 100.00 \\
\hline
\end{tabular}

SSI category, in majority of cases $(84.29 \%)$ was full length wound gap; followed by wound discharge in $8.57 \%$ women, and partial length wound gap in $5.00 \%$ women.

Median age of the women in cases group was comparable to that of control group ( 24 versus $23, \mathrm{p}=0.423$ ). Thus, there was no significant difference in cases and control groups in terms of age $(p>0.05)$. History of previous caesarean delivery were comparable among case and control group $(\mathrm{p}=0.407)$. There were significantly lesser number of booked subjects in cases group (64 versus 92, $\mathrm{p}=0.0008$ ), also there were significantly lesser median number of ANC visits in cases group (4 versus 5, $\mathrm{p}=0.001$ ).

As compared to control group, cases group had significantly higher number of women with mild Pre eclampsia (SBP 140-160 mmHg or DBP 90-110 mmHg) and severe pre eclampsia $(\mathrm{SBP}>160 \mathrm{mmHg}$ or $\mathrm{DBP}>110$ $\mathrm{mmHg}$ ) (38.57 versus 22.14, $\mathrm{p}=0.0006)$, significantly higher mean SBP $(132.07 \pm 21.14$ versus $123.77 \pm 11.76$, $\mathrm{p}=0.001)$, significantly higher mean DBP $(83.93 \pm 11.86$ versus $80.57 \pm 6.54, \mathrm{p}=0.008)$. There was significantly higher median BMI of women in cases group (22.45 versus 21.25, $\mathrm{p}<0.0001)$. Among the cases, $62.14 \%$ had anemia whereas among controls, $46.43 \%$ had anemia. The severity of anemia was higher among cases as compared to controls; with more grade $2 / 3$ anemia as compared to grade 1. There was a significant difference between cases and controls in terms of presence and grading of anemia $(\mathrm{p}=0.002)$. Presenting complaints were comparable between case and control groups $(\mathrm{p}>0.05)$. As compared to control group, there were significantly higher number of women with subcutaneous tissue thickness in cases group (20.00\% versus $5.71 \%, \mathrm{p}=0.0008)$.

Table 2: Comparison of host related parameters.

\begin{tabular}{|c|c|c|c|c|c|}
\hline Characteristics & $\begin{array}{l}\text { Cases } \\
(\mathrm{n}=140) \%\end{array}$ & IQR (cases) & $\begin{array}{l}\text { Control } \\
(\mathbf{n}=140) \%\end{array}$ & IQR (control) & $\begin{array}{l}\mathbf{p} \\
\text { value }\end{array}$ \\
\hline \multicolumn{5}{|l|}{ Age (years) } & \multirow{4}{*}{0.423} \\
\hline$\leq 20$ & $23(16.43)$ & \multirow{3}{*}{$24(21-27)$} & $6(4.29)$ & \multirow{3}{*}{$23.5(22-27)$} & \\
\hline $21-30$ & $108(77.14)$ & & $129(92.14)$ & & \\
\hline $31-40$ & $9(6.43)$ & & $5(3.57)$ & & \\
\hline History of previous LSCS & $19(13.57)$ & & $24(17.14)$ & & 0.407 \\
\hline ANC visit (booked) & $64(45.71)$ & $4(2-6)$ & $92(65.71)$ & $5(4-6)$ & 0.0008 \\
\hline \multicolumn{6}{|c|}{ Hypertensive disorder (BP in mmHg) } \\
\hline Mild pre eclampsia & $41(29.29)$ & \multirow{2}{*}{$\begin{array}{l}\text { SBP120 (120-150) } \\
\text { DBP80 (80-90) }\end{array}$} & $30(21.43)$ & \multirow{2}{*}{$\begin{array}{l}\text { SBP120 (120-130) } \\
\text { DBP80 (80-80) }\end{array}$} & \multirow{2}{*}{0.0006} \\
\hline Severe pre eclampsia & $13(9.29)$ & & $1(0.71)$ & & \\
\hline \multicolumn{6}{|l|}{ Anaemia (gm\%) } \\
\hline Grade 1 (mild 8-10.9) & $24(17.14)$ & & $30(21.43)$ & & \multirow{3}{*}{0.002} \\
\hline Grade 2 (moderate 5-7.9) & $52(37.14)$ & & $33(23.57)$ & & \\
\hline Grade 3 (severe <5) & $11(7.8)$ & & $2(1.43)$ & & \\
\hline \multicolumn{6}{|l|}{ Body mass index $\left(\mathrm{kg} / \mathrm{m}^{2}\right)$} \\
\hline Underweight $(<18.5)$ & $4(2.86)$ & \multirow{4}{*}{$\begin{array}{l}22.45 \\
(21.050-24.700)\end{array}$} & $3(2.14)$ & \multirow{4}{*}{$\begin{array}{l}21.25 \\
(20.200-22.350)\end{array}$} & \multirow{4}{*}{0.004} \\
\hline Normal (18.5-24.9) & $102(72.86)$ & & $125(89.29)$ & & \\
\hline Overweight (25-29.9) & $29(20.71)$ & & $11(7.86)$ & & \\
\hline Obese $(>30)$ & $5(3.57)$ & & $1(0.71)$ & & \\
\hline
\end{tabular}


Table 3: Comparison of intra-partum and procedure related parameters.

\begin{tabular}{|c|c|c|c|}
\hline Characteristics & Cases $(n=140)$ & Control (n=140) & P value \\
\hline \multicolumn{4}{|l|}{ Stage of labour } \\
\hline $1^{\text {st }}$ & $113(80.71)$ & $137(97.86)$ & \multirow{2}{*}{$<0.0001$} \\
\hline $2^{\text {nd }}$ & $17(12.14)$ & $3(2.14)$ & \\
\hline \multicolumn{4}{|l|}{ Antibiotics given } \\
\hline Injection ceftriaxone $1 \mathrm{gm}$, injection metronidazole $500 \mathrm{mg}$ stat & $139(99.29)$ & $140(100.00)$ & \multirow{2}{*}{1.000} \\
\hline Injection piptaz $4.5 \mathrm{gm}$, injection metro $500 \mathrm{mg}$ & $1(0.71)$ & $0(0.00)$ & \\
\hline \multicolumn{4}{|l|}{ No. of PV examinations done } \\
\hline$<4$ & $101(77.10)$ & $122(89.71)$ & \multirow{3}{*}{0.021} \\
\hline 4 to 8 & $28(21.37)$ & $13(9.56)$ & \\
\hline$>8$ & $2(1.53)$ & $1(0.74)$ & \\
\hline \multicolumn{4}{|l|}{ Duration of stage I of labour (hours) } \\
\hline$<12$ & $118(91.47)$ & $135(97.83)$ & \multirow{2}{*}{0.026} \\
\hline$>12$ & $11(8.53)$ & $3(2.17)$ & \\
\hline \multicolumn{4}{|l|}{ Duration of stage II of labour (hours) } \\
\hline$<1$ & $12(60.00)$ & $10(100.00)$ & \multirow{3}{*}{0.065} \\
\hline 1 to 2 & $5(25.00)$ & $0(0.00)$ & \\
\hline$>2$ & $3(15.00)$ & $0(0.00)$ & \\
\hline Elective LSCS & $5(3.57)$ & $2(1.43)$ & \multirow{2}{*}{0.447} \\
\hline Emergency LSCS & $135(96.43)$ & $138(98.57)$ & \\
\hline \multicolumn{4}{|l|}{ Indication of LSCS } \\
\hline Meconium stained liquor & $40(28.57)$ & $60(42.86)$ & 0.013 \\
\hline Ante partum haemorrhage & $5(3.57)$ & $2(1.43)$ & 0.447 \\
\hline Non-progression in 1st stage & $3(2.14)$ & $1(0.71)$ & 0.622 \\
\hline Non-progression in 2nd stage & $9(6.43)$ & $1(0.71)$ & 0.019 \\
\hline Pfannensteil incision & $140(100.00)$ & $140(100.00)$ & \\
\hline \multicolumn{4}{|l|}{ Operating time (hours) } \\
\hline$<1$ & $123(87.86)$ & $138(98.57)$ & \multirow{2}{*}{0.0005} \\
\hline$>1$ & $17(12.14)$ & $2(1.43)$ & \\
\hline \multicolumn{4}{|l|}{ Intra op blood loss (litres) } \\
\hline$<1$ & $133(95.00)$ & $138(98.57)$ & \multirow{2}{*}{0.173} \\
\hline$>1$ & $7(5.00)$ & $2(1.43)$ & \\
\hline \multicolumn{4}{|l|}{ Type of skin closure } \\
\hline Mattress & $138(98.57)$ & $139(99.29)$ & \multirow{2}{*}{1.000} \\
\hline Sub cuticular & $2(1.43)$ & $1(0.71)$ & \\
\hline \multicolumn{4}{|l|}{ Cadre of operating surgeon } \\
\hline Assistant professor & $60(42.86)$ & $36(25.71)$ & \multirow{7}{*}{0.021} \\
\hline Associate professor & $1(0.71)$ & $0(0.00)$ & \\
\hline Head of unit & $1(0.71)$ & $0(0.00)$ & \\
\hline First year resident & $1(0.71)$ & $1(0.71)$ & \\
\hline Second year resident & $7(5.00)$ & $3(2.14)$ & \\
\hline Third year resident & $66(47.14)$ & $95(67.86)$ & \\
\hline Senior resident & $4(2.86)$ & $5(3.57)$ & \\
\hline
\end{tabular}

As compared to control group, cases group had significantly lesser number of women in 1st stage duration more than 12 hours $(80.71 \%$ versus $97.86 \%, \mathrm{p}<0.0001)$ and significantly higher number of women in 2nd stage (12.14\% versus $2.14 \%, \mathrm{p}<0.0001)$. There was no significant difference in cases and control groups in terms of antibiotics $(\mathrm{p}=1.000)$. Regarding number of per vaginum examinations, cases group had significantly lesser number of women with $<4$ number of examination done $(77.10 \%$ versus $89.71 \%, \mathrm{p}=0.021)$; significantly higher number of women with 4 to 8 examination $(21.37 \%$ versus $9.56 \%, \mathrm{p}=0.021)$; and significantly higher number of women with $>8$ examination $(1.53 \%$ versus $0.74 \%$, $\mathrm{p}=0.021$ ).

Cases group had significantly higher number of women with duration of stage I $>12$ hours $(8.53 \%$ versus $2.17 \%$, $\mathrm{p}=0.026$ ). Duration of stage II was comparable in cases and control groups. 
There was no significant difference in cases and control groups in terms of type of LSCS ( $\mathrm{p}=0.447)$. Regarding indication of LSCS, as compared to control group, cases group had significantly lesser number of women with MSL (28.57\% versus $42.86 \%, \mathrm{p}=0.013)$; and significantly higher number of women with non-progression in 2 nd stage $(6.43 \%$ versus $0.71 \%, \mathrm{p}=0.019)$. Rest of indications such as antepartum haemorrhage and non-progression in 1st stage were comparable in cases and control groups $(\mathrm{p}>0.05)$.

Cases group had significantly lesser number of women in whom operative time was $<1$ hour $(87.86 \%$ versus $98.57 \%, \mathrm{p}=0.0005)$; and significantly higher number of women with operative time was $>1$ hour $(12.14 \%$ versus $1.43 \%, \mathrm{p}=0.0005)$. There was no significant difference in cases and control groups in terms of intra-operative blood loss $(\mathrm{p}=0.173)$. There was no significant difference in cases and control groups in terms of skin closure $(p=1.000)$. Regarding cadre of operating surgeon, as compared to control group, cases group had significantly higher number of women in whom LSCS was performed by Assistant professor (42.86\% versus $25.71 \%$, $\mathrm{p}=0.021$ ); significantly lesser number of women in whom LSCS was performed by third year resident $(47.14 \%$ versus $67.86 \%$, $\mathrm{p}=0.021$ ). There was a satistically significant difference between cases and control groups in terms of cadre of operating surgeon $(\mathrm{p}=0.021)$.

Table 4: Distribution of causative organism of cases.

\begin{tabular}{|lll|}
\hline Causative organism & Frequency & Percentage \\
\hline No organism & 83 & 59.29 \\
\hline Acinetobacter & 14 & 10.00 \\
\hline $\begin{array}{l}\text { Coagulase positive } \\
\text { Staphylococcus aureus }\end{array}$ & 1 & 0.71 \\
\hline E. Coli & 14 & 10.00 \\
\hline Enterococcus faecalis & 3 & 2.14 \\
\hline Klebsiella & 3 & 2.14 \\
\hline MRSA & 4 & 2.86 \\
\hline Pseudomonas & 13 & 9.29 \\
\hline Staphylococcus aureus & 5 & 3.57 \\
\hline Total & 140 & 100.00 \\
\hline
\end{tabular}

In majority of cases of sepsis, causative organism was Acinetobacter (in 10.00\%), E. coli (in 10.00\%), and Pseudomonas (in 9.29\%). Other causative organisms were Staphylococcus aureus, Enterococcus fecalis, Klebsiella, methicillin resistant Staphylococcus aureus (MRSA). No causative organisms was seen in $59.29 \%$ cases.

\section{DISCUSSION}

One of the common complications after a cesarean section (C-section) is the surgical site infections (SSI); these are primarily responsible for increase in maternal mortality and morbidity, less satisfaction of patients, long duration of hospital stays, and higher cost of treatment. ${ }^{2}$
In our study, there was no significant association of age with occurrence of SSI. The majority of patients in our study group belong to the age group of 21-30 years which could be because most pregnant women fall within this age distribution. Similar results were reported by Amoran et al who indicated that age had no significant association with SSIs. ${ }^{3}$

Increased BMI influence the outcome of surgery in terms of an increased rate of infection. Ketcheson et al found an association between surgical site infection after cesarean delivery with higher pre pregnancy weight and weight gain during pregnancy. ${ }^{4}$ They observed a dose-response relation between pre pregnancy weight and infection. Pre pregnancy obesity has been a significant and strong independent risk factor for surgical site infection in studies by Anderson et al and Marchi et al and, given its high prevalence, is therefore important., ${ }^{5,6}$ There was a significant association of SSI with presence and grading of anaemia $(p=0.002)$. In another study by Devi et al $48 \%$ of the patients had anaemia which is consistent with De et al study. ${ }^{7}$

We found significant association of ANC visits with SSI infections; women with SSI had less ANC visits ( $p=0.001$ ). In comparison to our study, Mamo et al found that ANC follow up, prior cesarean section, and circumstance of surgery had no statistically significant association with SSIs. ${ }^{8}$ History of previous caesarean delivery was not associated with SSI. Zejnullahu et al concluded that $14.1 \%$ had a history of previous C-section and a statistically significant association between SSI and history of previous C-section was found. ${ }^{2}$ Difference in findings of these studies from that of our study could be due to study setting. The studies, which are done in tertiary hospital, have high flow of referral cases. Most studies have concluded that patients with repeated $\mathrm{C}$-section were more likely to develop SSIs. The plausible reason behind is the fibrosis resulting from previous scar may impede tissue healing.

More women with SSI had mild and severe pre eclampsia. In this study, gestational diabetes was not present in any women. Compared to our study, Zejnullahu et al found that in their study $17(5.2 \%)$ women had hypertensive disease and $6(1.8 \%)$ had diabetes. ${ }^{2}$ Duration of ruptured membrane was more than 8 hours in women with SSI. Similarly, Mamo et al reported that duration of membrane rupture was significantly associated with SSIs; duration of greater than 12 hours were six times more likely to develop SSIs as compared to those mother duration of membrane rupture less than 12 hours. ${ }^{8}$ Women with SSI were associated with duration of labour stage I more than 12 hours, while stage II duration was similar in those with and without SSI. Mamo et al found that the duration of labour had statistically significant association with SSIs, those duration of labour more than 24 hours were two times more likely to develop SSIs as compared to those in whom duration of labour was less than 24 hours. ${ }^{8}$ 
There is strong evidence of the protective role of antibiotic prophylaxis to reduce the SSI rate with remarkable low SSI incidence rate among the patients with antibiotic administration prior to surgery. The main source of error in the clinical setting is usually the choice of the antibiotics related to procedure as well as dosing of the antimicrobials. ${ }^{9}$ While the timing and the dosing was a bit controversial, there are convincing data that administration of antibiotic $30 \mathrm{~min}$ prior to incision compared to the administration $60 \mathrm{~min}$ before incision is not associated with significant difference regarding the SSI rate. ${ }^{2,10}$

Differences in findings of our study with that of other studies related to the antibiotic prophylaxis prior to Csection are chiefly due to the lack of appropriate prenatal care in pregnant women, absent or inadequate screening for common bacterial infections during pregnancy and UTI, low socioeconomic status of the women, and importantly by local list of essential medicines used in our hospital.

Cases group had significantly more women with 4-8 or $>8$ PV examination $(\mathrm{p}=0.021)$. Type of LSCS (emergency/elective) was not associated with occurrence of SSI. Cases group had significantly lesser number of women with MSL and significantly higher number of women with non-progression in 2nd stage. Similarly, Vijayan et al found significant association of emergency/elective CS with SSI. Emergency surgeries have a high chance of SSI probably related to increased number of vaginal examinations and longer duration of rupture of membranes. ${ }^{11}$ In present study, type of incision for all study subjects was Pfannensteil incision. So no association was established between type of incision and SSI. Molla et al found that SSI was significantly associated with midline skin incision than operations done via Pfannensteil incision. ${ }^{12}$ Shreshtha et al also found similar association. In this study, in significantly more women with SSI, operative time was $>1$ hour. ${ }^{13}$ Similar findings were reported by Zejnullahu et al who found statistically significant associations between SSI versus duration of operation. ${ }^{2}$ Killian et al in which duration of operation $>1$ hour posed increased the risk for SSI development after $\mathrm{C}$-section and that prolonged surgery time is an independent risk factor for the development SSI. ${ }^{14}$ Intraoperative blood loss was not associated with SSI. Risk of surgical site infection increased by $30 \%$ for every $100 \mathrm{ml}$ blood loss. A high volume of blood loss is usually associated with poor control of bleeding, increased tissue damage from prolonged retraction and manipulation and more sutures. Molla et al reported that SSI was significantly associated with estimated blood loss (EBL) of greater than $500 \mathrm{ml} .^{12}$ Cases group had significantly higher number of women in whom LSCS was performed by assistant professor. Similarly, Vijayan et al found significant association of surgeon (consultant/surgeon) with SSI. ${ }^{7}$ The expertise of the surgeon usually protects against wound infection. Observation was on the contrary. The explanation may be as follows. High risk cases with BMI nearing 30, cases with severe pre-eclampsia, prolonged labour, second stage LSCS are generally performed by assistant professors on duty and not by residents. Residents are doing cases posted on an elective basis and uncomplicated cases with a faculty assisting them. In our study, presence of SSI was significantly associated with subcutaneous tissue thickness $>2 \mathrm{~cm}$. Subcutaneous tissue suturing was not done in any women in our study, so association could not be evaluated. Type of skin suturing was not associated with SSI. In comparison, Molla et al also reported that SSI was significantly associated with interrupted skin closure. ${ }^{12}$

On performing multivariate forward conditional logistic regression, number of ANC visits, haemoglobin, pre eclampsia, PROM, non-progression in 2nd stage and subcutaneous tissue thickness were the independent significant risk factors. With the increase in number of ANC visits and haemoglobin, risk of surgical site infection significantly reduced with odds ratio of 0.856 and 0.779 respectively. On the other hand, presence of severe preeclampsia, PROM >12 hours, non-progression in 2nd stage and subcutaneous tissue thickness $>2 \mathrm{~cm}$, risk of surgical site infection significantly increased with odds ratio of $1.0001,9.812,3.777,13.663$ and 7.083 respectively. Based on the independent risk factors identified, the modifiable risk factors are, number of ANC visits, hemoglobin levels (anaemia) and subcutaneous tissue thickness (obesity).

Strengthening pre conceptional counselling can help in identifying risk factors and their timely correction. Improvement in dietary habits may help in reducing prevalence of obesity. Correction of anaemia prior to pregnancy will also assist in reducing anaemia during pregnancy and labour.

This study was conducted in a setting which caters to patients belonging primarily to the lower or middle socioeconomic strata and the data primarily reflects the situation in this cohort. Being a single centre hospital based study, its results cannot be extrapolated to study the risk factors associated with cesarean section SSI in the general population. A limitation of the current study is the small sample size due to the short study period. A larger cohort study would further address more issues associated with SSI after CS. Risk factors leading to surgical site infecions post caesarean section like sterility of operation theatre, effectiveness of sterilisation and disinfection of the instruments, gowns and linen could not be assessed. Sample size had to be limited to 140 due to the limited study duration and also, some subjects had to be excluded from the study in view of exclusion criteria.

\section{CONCLUSION}

In conclusion, number of ANC visits, haemoglobin levels (anaemia), pre eclampsia, PROM, non-progression in 2nd stage and subcutaneous tissue thickness were the independent significant risk factors associated with postcesarean SSI. 


\section{ACKNOWLEDGMENTS}

Authors would like to thank the Dean, Medical College, Baroda and the Medical Superintendent, SSG Hospital, Baroda for permitting us to undertake this study.

\section{Funding: No funding sources}

Conflict of interest: None declared

Ethical approval: The study was approved by the Institutional Ethics Committee

\section{REFERENCES}

1. Bruce J, Russel EM, Mollison J. the measurement and monitoring of surgical adverse events. Health technology assessment. 2001;5:13-28.

2. Zejnullahu VA, Isjanovska R, Sejfija Z, Zejnullahu VA. Surgical site infections after cesarean sections at the University Clinical Center of Kosovo: rates, microbiological profile and risk factors. BMC Infect Dis. 2019;19:752.

3. Amoran OE, Sogebi AO, Fatigues OM. Rates and risk factors associated with surgical site infections in a tertiary Care Center in South-Western Nigeria. Int J Trop Dis Health. 2013;3(1):25-36.

4. Ketcheson F, Woolcott C, Allen V, Langley JM. Risk factors for surgical site infection following cesarean delivery: a retrospective cohort study. CMAJ Open. 2017;5(3):546-56.

5. Anderson V, Chaboyer W, Gillespie B. The relationship between obesity and surgical site infections in women undergoing BIBLIOGRAPHY 125 caesarean sections: an integrative review. Midwifery. 2013;29:1331-8.

6. Marchi J, Berg M, Dencker A. Risks associated with obesity in pregnancy, for the mother and baby: a systematic review of reviews. Obes Rev. 2015;16:621-38.

7. De D, Saxena S, Mehta G, Yadav R, Dutta R. Risk factors analysis and microbial etiology of surgical site infections following lower segment caesarean section. Int J Antibiot. 2013;10:1155-60.

8. Mamo T, Abebe TW, Chichiabellu TY, Anjulo AA. Risk factors for surgical site infections in obstetrics: a retrospective study in an Ethiopian referral hospital. Patient Safety Surg. 2017;11:24

9. Steinberg JP, Braun BI, Hellinger WC, Kusek L, Bozikis MR, Bush AJ, et al. Timing of antimicrobial prophylaxis and the risk of surgical site infections: results from the trial to reduce antimicrobial prophylaxis errors. Ann Surg. 2009;250(1):10-6.

10. Royal College of Obstetricians and Gynaecologists (RCOG) Clinical guideline for caesarean section. Elective and emergency (V.10) London: RCOG. 2016.

11. Vijayan CP, Mohandas S, Nath AG. Surgical Site Infection following cesarean section in a teaching hospital. Int J Sci Stud. 2016;3(12):97-101.

12. Molla M, Temesgen K, Seyoum T, Melkamu M. Surgical site infection and associated factors among women underwent cesarean delivery in Debretabor General Hospital, Northwest BIBLIOGRAPHY 126 Ethiopia: hospital based cross sectional study. BMC Preg Childbirth. 2019;19:317.

13. Shrestha S, Shrestha R, Shrestha B, Dongol A. Incidence and risk factors of surgical site infection following cesarean section at Dhulikhel hospital. Kathmandu Univ Med J. 2015;12(2):113-6.

14. Killian CA, Graffunder EM, Vinciguerra TJ, Venezia RA. Risk factors for surgical-site infections following cesarean section. Infect Control Hosp Epidemiol. 2001;22:613-7.

Cite this article as: Rano R, Patel PK. Analysis of risk factors associated with caesarean section surgical site infections: a case control study. Int J Reprod Contracept Obstet Gynecol 2020;9:5075-81. 